\title{
Study on the Effect of Wine Culture Capital on Business Performance Xue-Dong $\mathrm{BAO}^{1,2, a}$, Yong-Zhong YANG ${ }^{1, b *}$ \\ ${ }^{1}$ Bussiness School of Sichuan University, Chengdu, Sichuan, China \\ ${ }^{2}$ Leshan Vocational and Technical College, Leshan, Sichuan, China \\ axudonging@163.com, byangyongzhong116@163.com \\ ${ }^{*}$ Corresponding author
}

Keywords: Cultural capital, Wine cultural capital, Business performance.

\begin{abstract}
Cultural industries have been flourishing with the growing demand of people for cultural consumption, and cultural capital has become one of the important forms of capital in the business development and affected the business activities both from internal and external system. This paper is based on the background of cultural industries' rapid development in China, and focus on the Chinese wine culture capital. According to the results of empirical analysis based on the data collected from 8 listed companies on Chinese A stock, we found that the cultural capital of wine has a significant positive impact on the liquor business performance. On the one hand, wine cultural capital reflects the people's essential characteristics of production and consumption of wine, and become the fundamental basis for people to do relevant selection. On the other hand, the wine cultural capital can promote the formation of social demand and consumption structures by guiding people's needs, even affect and constraint the related systems arrangements, technological progress and the allocation of resources to optimize the operation of wine business.
\end{abstract}

\section{Introduction}

China has a long history of making and drinking spirit or Chinese wine. According to legend, the Chinese people began to make spirit with grains seven thousand years ago and even earlier with animal milk. During the long history of making spirit and drinking, it has accumulated special Chinese wine culture and became an important part of Chinese traditional culture. Generally, Chinese wine culture includes intangible social culture, such as the legend, the literature and the custom of spirit, as well as the wine cellar, ruins, celebrities, city and other tangible things. With the escalating of consumption demand, the impact of culture on commodity production and consumption become increasingly significant, wine culture affects wine production and consumption by its special form as well.

Firstly, the custom followed by the people during the communication plays a role in the behavior of wine culture. Wei-cheng Wan considered these acts as a kind of behavior patterns in the forms of, spirit customs, spirit beliefs, drinking games and community activities [1]. Taking the spirit etiquette for example, it not only plays a role in ruling the country, educating the people, and governing the riots, but also becomes a normal code in weddings, festival customs, eating habits, treating and finishing of folk rituals. Secondly, the people's values can promote the innovation to the packaging and advertising of wine and the natural conditions also restrict the liquor brewing and contribute to the formation of drinking customs, which makes the wine culture presents obvious regional characteristics.

In addition, the wine culture can also affect the business culture. Xue-gong Li considered the wine culture also includes the culture created by the wine organizations in the process of production and management, and the wine cultural resources were essentially "the knowledge value system of Chinese wine enterprise by scientifically developing and utilizing of cultural resources and implying an integrated management strategy"[2]; Yong-gui Zhao etc. studied the culture and values of Wuliangye liquor company, and considered that business culture had integrated liquor culture[3].

With the development of cultural industries, wine culture becomes increasingly important for wine business, but how to effectively integrate the wine cultural resources with cultural resources to 
cultural capital which can be injected into the product design, production, marketing and even build a wine cultural creative industry (such as wine culture tourism and experience shows etc.) in order to meet the consumers' demand and enhance the competitiveness of wine enterprises?

\section{The cultural capital of liquor}

\section{The conception}

Economists generally divide capital into physical capital, human capital, intellectual capital and institutional capital and so on. In 1990, a French sociologist Pierre Bourdieu firstly proposed the concept of cultural capital and applied it to sociology and culture study, and he pointed out that individuals who can adapt to a higher level of social culture would have cultural capital [4]. In 1998, a professor of economics named David Throsby invited the conception of "cultural capital" to the areas of economics and considered it one of the four types, namely, physical capital-refers to the commodity stocks in real substance as factories, machinery, buildings, etc., human capital—refers to the capital stock reflected by the skills and experience of people, natural capital-refers to the renewable and non-renewable natural resources supplied by nature and the ecological processes which play a role in the existence and use of these resources, cultural capital-refers to the number of cultural capital on a certain point and services flow over time caused by the cultural capital, furthermore cultural capital has both cultural and economic value, and it should be considered the sustainability of cultural capital as the natural capital [5].

This paper invited the conception of cultural capital from Throsby and defined the wine cultural capital stock of a liquor company as the number of cultural capital existed on a certain time and can be measured by any kind of appropriate accounting unit as total number or total value, and these stocks would generate services flows over time for consumption or reproduction.

\section{The composition}

Considering the composition of the cultural capital, Bourdieu considered the cultural capital could be divided into three forms: cultural competence, cultural product and cultural institution. Throsby considered the same as other types of capital, cultural capital have stocks, and exists in both the tangible and intangible forms. Pei-xin Li believed the cultural capital consisted of three types of shaped structure according to the cultural types, that is, solid cultural capital, product cultural capital and cultural capital flows [6].

when it comes the wine cultural capital, it also can be divided into two categories of tangible and intangible, the tangible cultural capital include the solid and product capital as Pei-xin Li proposed [6], such as the ruins, packages, etc.; the intangible cultural capital includes the cultural competence capital and institutionalized cultural capital as Bourdieu described, such as brewing techniques, the custom of spirit, celebrations and other non-material cultural achievements.

\section{The assessment}

The wine culture capital is too abstract to assessment. Throsby thought that cultural capital can be estimated in using the capital investment analysis techniques the same as other traditional forms of capital, and evaluated the cultural heritage market gains by the cost-benefit analysis, as well as travel cost method, hedonic pricing method and other economic evaluation methods [5]. UNESCO (McKinley, T., 1997) and New Zealand (Cultural Indicators for New Zealand: 2006) valued the cultural capital by constructing the index system.

\section{Data and Methodology}

\section{Data collection}

Given the characteristics of the wine culture, when we discuss the liquor culture capital we refer to the stock of liquor cultural capital of a liquor company at a certain time. In order to collect 
accurate and real data, we choose the liquor companies listed on the Chinese A stock from 2001 to 2011 except companies without complete data or marked by * ST/ST, then we get data from the annual report of 8 companies (see table 1).

Table 1: The liquor companies

\begin{tabular}{clcc}
\hline No. & \multicolumn{1}{c}{ The full name of company } & abbreviation & Listed time \\
\hline 1 & Zhejiang Gu Yue Long Shan Shaoxing Wine Co.,Ltd & Gu Yue Long Shan & $1997-05-16$ \\
2 & Xingjiang Yilite Group Co., Ltd & Yilite & $1999-09-16$ \\
3 & Sichuan Tuopai Shede Wine Co., Ltd. & Tuopai Shede & $1996-05-24$ \\
4 & Sichuan Swellfun Co.,Ltd & Swellfun & $1996-12-06$ \\
5 & Shanxi Xinghuacun Fen Wine Factory Co.,Ltd & Shanxi Fen Wine & $1994-01-06$ \\
6 & Wuliangye Yibin Co.,ltd & Wuliangye & $1998-04-27$ \\
7 & Kweichow Moutai Co.,Ltd & Kweichow Moutai & $2001-08-27$ \\
8 & Luzhoulaojiao Co.,Ltd & Luzhoulaojiao & $1994-05-09$ \\
\hline
\end{tabular}

\section{Variables}

In order to investigate the relationship between the cultural capital of spirit and business performance, we set variables as follows:

Dependent variables: the dependent variable is the output of a company and represented by LP. We invite the prime operating revenue to represent the output of a company in order to get a comprehensive reflection of efficiency in the use of physical capital, human capital and cultural capital, and reduce the capital consuming of other businesses to some extent.

Independent variables: the independent variables refer to all kinds of capital stock which are invested in businesses, including physical capital, human capital and cultural capital. The physical capital (MC) mainly refers to the physical capital stock at a certain point of time on the business, including machinery and equipment, plant, land, etc., and can be measured by fixed assets; human capital (HC) refers to the human capital stock owned by the enterprises at a certain point of time, and can be estimated by the educated estimation method based on the years of employees' education; cultural capital (CC) refers to the culture capital stock of wine owned by the enterprise at a certain point of time, and can be represent by a collection of cultural capital including National Cultural Heritage Conservation Board, Intangible Cultural Heritage, China's Prominent Trademark, China's Prominent Spirit and Product of Geographical Indication (see Table 2 ).

Control variables: we set the control variables to get rid of the effects of other variables on the business performance of the enterprise. The business performance of a company is closely related to the scale of the company. If the scale of the company is larger, it may own and control more resources, and it may be easier to achieve the economies of scale and its business performance may be better. The asset size or the number of employees is usually used to measure the size of the company. We invite the total assets to represent the scale of the company by S. The company's specific knowledge and capabilities can be gradually accumulated over time, and the knowledge and ability can affect the business performance. The longer operating life of the enterprise, the more likely to get knowledge advantage, experience advantages and capability strengths, thus contributing to the improvement of business performance, and therefore the company age (Y) should be a control variable. 
Table 2: The cultural capital owned by the company

\begin{tabular}{|c|c|c|c|c|c|c|}
\hline & $\begin{array}{c}\text { Intangible } \\
\text { Cultural } \\
\text { Heritage }\end{array}$ & $\begin{array}{l}\text { China's } \\
\text { Prominent } \\
\text { Trademark }\end{array}$ & $\begin{array}{l}\text { Product of } \\
\text { Geographical } \\
\text { Indication }\end{array}$ & $\begin{array}{c}\text { China's } \\
\text { Prominent } \\
\text { Spirit }\end{array}$ & $\begin{array}{c}\text { National Cultural } \\
\text { Heritage } \\
\text { Conservation } \\
\text { Board } \\
\end{array}$ & $\begin{array}{l}\text { The stock of } \\
\text { cultural } \\
\text { capital }\end{array}$ \\
\hline Gu Yue Long Shan & 1 & 1 & & & & 2 \\
\hline Yilite & & 1 & & & & 1 \\
\hline Tuopai Shede & 1 & 2 & & 1 & 1 & 5 \\
\hline Swellfun & 1 & 1 & 1 & & 1 & 4 \\
\hline Shanxi Fen Wine & 1 & 2 & & 1 & 1 & 5 \\
\hline Wuliangye & 1 & 3 & 1 & 1 & & 6 \\
\hline Kweichow Moutai & 1 & 2 & 1 & 1 & & 5 \\
\hline Luzhoulaojiao & 1 & 3 & 1 & 1 & 1 & 7 \\
\hline
\end{tabular}

\section{Model}

We set models to explore the impact of the liquor cultural capital on the business performance based on the Cobb-Douglas production function and build four multiple linear regression equations. Eq. 1 is a binary production function on physical capital and human capital without intercept, Eq. 2 is a binary production function on physical capital and human capital with intercept, Eq. 3 introduces the cultural capital to the model 2, the control variables is added to Eq. 4, as follows:

$$
\begin{aligned}
& \ln L P=\beta_{1} \ln M C+\beta_{2} \ln H C+\varepsilon . \\
& \ln L P=\beta_{0}+\beta_{1} \ln M C+\beta_{2} \ln H C+\varepsilon . \\
& \ln L P=\beta_{0}+\beta_{1} \ln M C+\beta_{2} \ln H C+\beta_{3} \ln C C+\varepsilon . \\
& \ln L P=\beta_{0}+\beta 1 \ln M C+\beta_{2} \ln H C+\beta_{3} \ln C C+\beta_{4} S+\beta_{5} T+\varepsilon .
\end{aligned}
$$

Where: In represents natural logarithm, LP is the output of company; $\mathrm{S}$ is the natural logarithm of total assets in order to eliminate the impact of the trend; $\beta_{0}$ is the intercept; $\beta_{i}(i=1,2,3,4,5)$ is the estimated regression coefficients representing the marginal contribution of the corresponding variables on the dependent variable; $\varepsilon$ is a random disturbance term and normally distributed.

\section{Results and discussion}

We estimate the above models by the ordinary least squares method (OLS) and the results are shown in Table 3. The statistic test for each model is significant. Referring to the adjusted R-squared, with the introduction of the variables in turn, the ability of the model to explain the dependent variable is gradually increased, when we introduce the "cultural capital" and the control variables, it is as high as $93.23 \%$.

All of the stocks of physical capital, human capital and cultural capital have certain influence on the output of the liquor business, but the influence is gradually weak with the adding types of capital invested. When we introduce the control variable of enterprise-scale, the direction of action of physical capital is negative, indicating that with the expansion of business scale, which has been unable to effectively promote the enterprises to improve the level of output just relying on physical capital investment. Apparently it follows the law of diminishing marginal returns. The human capital has a positive effect on the output of enterprises. The parameters of human capital are significant and above 0.32 , indicating that the human capital plays a key role in the output of the liquor business. In addition, two control variables of time listed and enterprise scale are positive to the output of company, indicating that the output level of the liquor business are proportional to the scale and life of enterprise, the larger the size of companies and longer the standardization operating, the higher the output level. 
Table 3: The results

\begin{tabular}{lcccc}
\hline Variable & Model 1 & Model 2 & Model 3 & Model 4 \\
\hline $\mathrm{C}$ & & $9.9600 * * *$ & $11.2485^{* * *}$ & $-0.1978 * * *$ \\
$\mathrm{MC}$ & $0.8013 * * *$ & 0.1127 & 0.0906 & $-0.2398 * * *$ \\
$\mathrm{HC}$ & $0.4465 * * *$ & $0.8506 * * *$ & $0.7204 * * *$ & $0.3171^{* * *}$ \\
$\mathrm{CC}$ & & & $0.3992^{* * *}$ & $0.1236^{* * *}$ \\
$\mathrm{~S}$ & & & & $1.0344 * * *$ \\
$\mathrm{~T}$ & & & & $0.0172 * * *$ \\
R-squared & 0.4436 & 0.6099 & 0.6499 & 0.9361 \\
Adjusted R-squared & 0.4371 & 0.6007 & 0.6374 & 0.9323 \\
F-statistic & $68.5600 * * *$ & $66.4349 * * *$ & $51.9773 * * *$ & $240.4326 * * *$ \\
\hline
\end{tabular}

Note: *** indicates significant at $1 \%$ level.

The estimated coefficient of cultural capital in the model 3 is 0.3992 and 0.1236 in model 4, indicating that the cultural capital stock does have a significant impact on the level of output of liquor business and the output of liquor business is proportional to the stock of cultural capital. But how does the cultural capital of wine promote the business performance?

The cultural capital of wine is a collection of people's knowledge, beliefs, perceptions and ways of thinking of wine, on the one hand, it reflects the people's essential characteristics of production and consumption of wine, and becomes the base for people to do relevant selection, so we can guide people's needs by accumulating the wine culture capital. One the other hand, the wine cultural capital can promote the formation of social demand and consumption structures (consuming attitudes, the way of consumption, etc.) by guiding people's needs (tastes, preferences, etc.), thus potentially affects and constraints the related systems arrangements, technological progress and the allocation of resources to optimize the operation of wine business. Besides, with the escalating needs for culture of the people, the cultural capital of wine has become important means to enhance the corporate brand and increase value-added, even the wine cultural resources have been developed to an independent industry supporting the enterprise's development on the background of cultural industry or the creative industry.

\section{Conclusions}

This paper analyzes the cultural capital of liquor and found it play an important role in business performance of liquor companies, which is an important reference to operation and development of enterprises. It's a wise strategy to integrate liquor cultural resources with cultural capital. Liquor companies should fully exploit their own cultural resources in order to form a unique cultural capital and "implant" the culture into the product. In fact, this process is how to get the consumers to identify the wine culture, or the process of how to spread wine culture. The process of acceptance of product for consumer is stared with recognizing, then to know and be familiar, and end with identifying. It may be recognized when the cultural elements, mood, etc. carried by commodities match the identity of consumers. Therefore, the development of wine cultural resources should focus on specific audiences, rather than aimlessly indiscriminate development.

The development of liquor cultural recourses needs the integration of culture and technology. When we realize the integration of and cultural capital, the technology capital can enter people's value systems and be accepted and utilized by people. Therefore, the development and utilization of cultural capital should never be fabrications.

To develop wine cultural creative industries is an efficient way to develop and utilize the wine cultural capital. Liquor companies should make full use of their cultural capital, change the mode of business development and adjust to the industrial structure to improve business performance by developing wine cultural creative industries through the integration of culture, economy and technology. 


\section{Acknowledgement}

We gratefully acknowledge the research support received from the National Natural Science Fund (71173150), the Key Project of the National Social Science Fund (12AZD018), Program for New Century Excellent Talents in University (NCET-12-0389), the key project of System Science and Enterprise Development Center of Sichuan Province (XQ12A01) and the key project of Research Center for Sichuan Liquor Industry Development(CJZ12-02).

\section{References}

[1] Wei-cheng Wan. Connotation, morphological characteristics and trends of Chinese wine culture. Journal of Brewing Technology, 9 (2007) 104-108.

[2] Xue-gong Li. The core growth strategy Chinese liquor brand-integrated management of cultural resources. The journal of Chinese trademark. 9 (2001) 39-40.

[3] Yong-gui Zhao. The connotation and significance Wuliangye's liquor culture. The Journal of forum on Chinese culture. 4 (2009) 158-160.

[4] Pierre Bourdieu, Ya-ming Bao trans. Cultural Capital and Social Alchemy. Shanghai People's Publishing House, 1997, in Chinese.

[5] David Throsby, Zhi-biao Wang, Zheng-rong Zhang trans. Economics and Culture. China Renmin University Press , 2011, in Chinese.

[6] Pei-xin Li. Cultural capital - theory and practice research on cultural capital operations. Ph.D. Thesis. Minzu University of China. 2006.

[7] David Hesmondhalgh, Fei-na Zhang trans. The cultural industries. China Renmin University Press , 2007, in Chinese.

[8] Xiang-yu Jin, Peng Wu. Study on the relationship between cultural capital and regional economic development. Journal of Statistical Research , 26 (2009) 28-34.

[9] Yi-xi Huang. Wine, wineset and traditional culture: the study of the wine culture of ancient China. Ph.D. Thesis. Xiamen University. 2008.

[10] Wu-wei Li, Hui-min Wang. Creative Industry Promoting the Changing of the Ways of Economic Growth. Journal of China 's industrial economy , 11 (2006) 4-13. 